\title{
A EDUCAÇÃO FÍSICA NA FORMAÇÃO DE PROFESSORES NORMALISTAS (1897-1921)
}

PHYSICAL EDUCATION IN THE TRAINING OF NORMAL SCHOOL STUDENT TEACHERS (1897-1921)

LA EDUCACIÓN FÍSICA EN LA FORMACIÓN DE PROFESORES

NORMALISTAS (1897-1921)

\section{Tony Honorato*}

\begin{abstract}
Palavras-chave História.

Ginástica.

Docentes.

Educação.

Resumo: A partir da pesquisa referente à Escola Complementar e Normal de Piracicaba/ $\mathrm{SP}$, a proposição é compreender a presença da Educação Física na formação de professores (1897-1921). Como fontes históricas têm-se os dispositivos legais, os manuscritos de diretores escolares, a Revista de Educação e anuários de ensino. Os resultados indicam que a idealizada educação integral do homem foi processual e estruturalmente lenta nas escolas modelares do Estado de São Paulo no período da primeira República.
\end{abstract}

\section{Keywords:}

History.

Gymnastics.

Teachers.

Education.

\section{Palabras clave}

Historia.

Gimnasia.

Docentes.

Educación.

Abstract: From the research regarding the Supplementary and Normal School of Piracicaba/SP, the proposition is to comprehend the presence of Physical Education in the training of teachers (1897-1921). Historical sources include legal devices, school principals' manuscripts, the journal Revista de Educação and teaching yearbooks. The results indicate that idealized men's integral education was procedurally and structurally slow in model schools of the State of Sao Paulo during the time of the so-called First Republic.

Resumen: A partir de una investigación sobre la Escola Complementar e Normal de Piracicaba/SP, la propuesta es comprender la presencia de la Educación Física en la formación de profesores (1897-1921). Como fuentes históricas son utilizados los dispositivos legales, los manuscritos de directores escolares, la Revista de Educación y anuarios de enseñanza. Los resultados indican que la idealizada educación integral del hombre fue gradual y estructuralmente lenta en las escuelas modelo del Estado de São Paulo durante el período la Primera República.
* Universidade Estadual de Londrina (UEL). Londrina, PR. Brasil. E-mail: tony@uel.br

Recebido em: 17-10-2014

Aprovado em: 23-03-2015 


\section{INTRODUÇÃO}

Este estudo buscou evidenciar a presença da Educação Física na formação de professores na Escola Complementar e Normal (1897-1921), localizada na cidade de Piracicaba, no estado de São Paulo. O fato é que a Educação Física compunha a realidade da cultura escolar no final dos oitocentos, isso em razão da exigência de se preparar cidadãos de forma integral - física, moral e intelectual -, incumbência atribuída aos professores escolares que educariam os filhos da modernidade republicana.

Nas escolas do final do século XIX e início do XX, a Educação Física era, inicialmente, desenvolvida no conjunto de atividades práticas das aulas de Ginástica, Exercícios Militares, Música, Noções de Higiene, Trabalhos Manuais, Economia Doméstica etc. A análise ora proposta está circunscrita à Ginástica.

Destaca-se que o termo Educação Física, no período pesquisado e na realidade analisada, não remetia a uma disciplina escolar específica do programa de formação de professores, remetia, como asseveram Moreno et al. (2012), a uma dimensão da educação do corpo e das sensibilidades múltiplas dos sentidos presente em diferentes componentes curriculares que fomentavam a relação entre a aprendizagem e o corpo. Assim, para disseminar os valores de saúde pública e individual, de disciplina social e cívica, de (auto)controle corporal e de higiene para uma vida positiva, prática e útil em sociedade, os estudantes, quando em formação de professores, deveriam aprender em diferentes disciplinas como cuidar do próprio corpo para, então, no futuro, ensinar o outro a cuidar de si na vida social.

Neste sentido, saberes e práticas de cultivo físico deveriam ser institucionalizados, introduzidos, estruturados e consolidados nas escolas primárias, modelos, complementares, normais e secundárias previstas na Reforma da Instrução Pública do Estado de São Paulo, conformada na Lei n. 88 de setembro de 1892'. Essa Reforma era audaciosa porque, para atendê-la, o Estado demandaria a construção de muitas escolas e a preparação de um alto coeficiente de professores nos moldes modernos, que até então eram diplomados somente pela Escola Normal da Capital. A solução foi criar no interior paulista escolas complementares para diplomar professores, no caso a de Piracicaba, a de Itapetininga e, posteriormente, a de Campinas e a de Guaratinguetá.

A Escola Complementar de Piracicaba foi eleita para este estudo como objeto empírico de investigação em razão de representar uma das primeiras a diplomar professores complementaristas e por ter sido uma instituição modelar na formação de professores na sociedade paulista. Ela foi instalada em 1897, em 1911 foi convertida em Escola Normal Primária e em 1921 passou a funcionar como Escola Normal tal como suas congêneres (HONORATO, 2011). O processo histórico entre 1897 e 1921 indica a periodização da documentação consultada e analisada.

Como fonte referente ao período histórico, assumiu-se a legislação da instrução pública paulista identificada no Centro de Referência para Pesquisa Histórica em Educação (CRPHE) da Universidade Estadual Paulista (FCLAr/UNESP); Revista de Educação e imagens iconográficas, bem como relatórios, ofícios, livros de inventário escolar manuscritos pelos diretores da Escola Complementar e Normal de Piracicaba, documentação acondicionada no 
arquivo permanente da Escola Estadual "Sud Mennucci" e no Arquivo Público do Estado de São Paulo. As fontes consultadas, nos termos de Chartier (1990) e Viñao Frago (2008), indicam as práticas e representações da matéria de Ginástica, bem como de uma dimensão educativa na cultura escolar de formação de professores: a Educação Física.

\section{PROGRAMA PARA FORMAÇÃO DE PROFESSORES NO ENSINO COMPLEMENTAR E NO NORMAL}

A reforma da instrução pública paulista de 1892 estabelecera três níveis de ensino: primário, secundário e superior. Fato que demandaria um alto número de professores primários, pois, segundo a lei, se previa a implantação de uma escola preliminar onde houvesse de 20 a 40 crianças em idade escolar. 0 ensino primário compreenderia o curso preliminar e 0 curso complementar. Obrigatório para crianças de sete a doze anos, o curso preliminar seria regido por professores normalistas, sendo ofertado em escolas preliminares ou nas auxiliares intermédias e provisórias. As escolas intermédias seriam regidas por professores habilitados conforme os regulamentos de 1869 e 1887, e as escolas provisórias deveriam ter professores interinos examinados pelos inspetores de distrito ou comissões municipais (SÃO PAULO, 1893, p. 20-22).

O curso complementar seria destinado aos alunos habilitados no ensino preliminar, preenchendo a lacuna entre o ensino preliminar e o secundário; para tanto, ofertaria um programa de ensino propedêutico. Entretanto, como o Estado de São Paulo tinha dificuldades com a falta de professores e de recursos financeiros, os reformadores da instrução pública indicaram como paliativo ao problema as escolas complementares. O governo republicano paulista atribuiu às escolas complementares a incumbência de diplomar professores. $O$ Projeto de Lei n. 61 de 1895, conformando a Lei n. 374, de 3 de setembro de 1895, previu em seu artigo 1, parágrafo único: "Os alunos que concluírem o curso complementar e tiverem um ano de prática de ensino, cursado nas escolas-modelo do Estado, poderão, na forma da lei, ser nomeados professores preliminares com as mesmas vantagens concedidas aos diplomados pela Escola Normal".

No estado de São Paulo formaram-se professores até 1911 em quatro escolas complementares (Piracicaba, 1897; Itapetininga, 1897; Campinas, 1903; Guaratinguetá, 1903)2 e na Escola Normal da Capital. De 1911 a 1921 em escolas normais primárias (Piracicaba, Campinas, Guaratinguetá, Pirassununga, Botucatu, Casa Branca e Brás) e normais secundárias (Capital, Itapetininga e São Carlos). Depreende-se que existiram dois modelos interdependentes voltados à preparação de professores ${ }^{3}$.

Em foco, a Escola Complementar de Piracicaba, desde sua criação, em 1897, preparava professores para o magistério. 0 ensino ofertado tomava como referência as inovações pedagógicas produzidas na Escola Normal da Capital, porém sem desprezar a sua própria capacidade de formar e de produzir inovações para a cultura geral. Ela tinha um programa curricular conforme o fixado pelo Decreto n. 400, de 6 de novembro de 1896:

2 Na cidade de São Paulo, desde 1895, havia também a Escola Complementar Anexa à Escola Normal da Capital e a Escola Complementar 'Prudente de Moraes', criada em 1897. Esta última foi extinta quando transferida, por força do Decreto Lei nº. 861 , de 12 de dezembro de 1902, para a cidade de Guaratinguetá.

3 Sobre as escolas normais primárias e secundárias paulistas, consultar: Rodrigues (1930); Rocco et al (1946); Tanuri (1979); Monarcha (1999); Nosella; Buffa (2002); Pinheiro (2003); Weber (2003); Azevedo (2005); Simões (2005); Teixeira Júnior. (2005); Frankfurt (2006); Chiareli (2007); Nery (2010); Dias (2009); Silva (2009); Corbage (2010); Honorato (2011). 
1‥ Ano - Português, Francês, Aritmética, Geografia do Brasil, História do Brasil, Caligrafia, Desenho e Exercícios de ginásticas.

$2^{\circ}$. Ano - Português, Francês, Álgebra, Escrituração Mercantil, Geometria plana e no espaço, Educação Cívica (Noções gerais da Constituição Pátria e do Estado), Desenho e Exercícios Militares.

3ํ. Ano - Português, Elementos de Trigonometria e Mecânica, Cosmografia, Geografia e História Geral, Trabalhos Manuais apropriados à idade e ao sexo e Exercícios Ginásticos.

4‥ Ano - Física, Química, História Natural, Noções de Higiene, Economia Doméstica e Exercícios Ginásticos. (SÃO PAULO, 1896, p. 2).

Duas das diferenças em relação à Escola Normal da Capital podem ser destacadas no programa acima. A primeira concerne a quatro professores "enciclopédias vivas"4, como eram denominados pelos diretores, um para cada ano, enquanto que a Escola Normal necessitava de 16 catedráticos, um para cada cadeira do currículo, e sete mestres de aulas de como Música, Ginástica, Trabalhos Manuais; a segunda diferença consiste na inexistência da disciplina de Pedagogia no programa.

Com a organização prescrita acima, a Escola Complementar de Piracicaba funcionou até 1911, quando foi convertida, no contexto da Reforma de Ensino, conhecida como "Oscar Thompson", em Escola Normal Primária, passando a ter o seguinte programa curricular:

1‥ Ano - Português, Francês, Aritmética, Geografia Geral, Música, Trabalhos Manuais, Ginástica e Desenho.

2‥ Ano - Português, Francês, Álgebra, Geometria plana com aplicação às medidas, Geografia do Brasil, Pedagogia, Música, Trabalhos Manuais, Ginástica e Desenho.

3‥ Ano - Português, Francês, Geometria no espaço, História Universal, Noções de Física e Química, Pedagogia, Música, Trabalhos Manuais, Ginástica e Desenho.

4․ Ano - Português, Francês, História do Brasil, História Natural com aplicação à agricultura e à zootecnia, Pedagogia e Educação cívica, Música, Trabalhos Manuais (sexo masculino), Economia doméstica (sexo feminino), Ginástica e Desenho. (SÃO PAULO, 1911, p. 01).

Em relação às escolas normais secundárias, a Escola Normal Primária de Piracicaba ofertava seu programa sem a cadeira Psicologia Experimental e sem os gabinetes de Psicologia Experimental e de Pedagogia Antropológica. Entretanto, a presença da cadeira Pedagogia passa a ser notável em todos os anos do curso normalista primário.

Nota-se que nas prescrições legais supracitadas as matérias eram distribuídas em cadeiras (disciplinas) e aulas (atividades, exercícios, práticas) ${ }^{5}$. Segundo Tanuri (1979, p. 88), "a diferença parecia basear-se no fato de serem as cadeiras preenchidas por concurso e as aulas atribuídas a professores contratados sob a proposta do diretor da escola". Considerando as orientações de Viñao Frago (2008) para o estudo histórico das disciplinas escolares, as diferenciações também são fontes de poder e de profissionalização docente. No caso da realidade paulista pesquisada, as cátedras davam maior reconhecimento socioprofissional, os lentes catedráticos auferiam melhores salários do que os mestres de aulas específicas, tinham 
regime de trabalho mais estáveis em relação aos mestres que poderiam ser dispensados a qualquer momento, e ainda lecionavam saberes com status de escolarização elementar consolidada.

Para além da instrução elementar, observa-se que, sobretudo no programa para formação de professores, complementaristas e normalistas, a educação dos sentidos corporais e estéticos compôs o processo formativo na interação com diferentes saberes curriculares. Isso implicou a formalização, sistematização e consolidação de matérias como Ginástica, Exercícios Militares, Trabalhos Manuais, Desenho, Música e Canto Orfeônico, voltadas ao cultivo físico e artístico, cujo objetivo consistia em levar os indivíduos a comportarem-se de maneira mais saudável, integral, polida, completa e civilizada.

A seguir serão apresentadas a introdução da Ginástica e algumas questões da Educação Física na preparação de professores em uma realidade específica, a Escola Complementar e Normal de Piracicaba (1897-1921).

\section{INTRODUÇÃO E ESTRUTURAÇÃO DA GINÁSTICA NA ESCOLA COMPLEMENTAR E NORMAL DE PIRACICABA}

Nos relatórios dos diretores da Escola Complementar e Normal Primária de Piracicaba (1897-1921) observam-se, entre outros, registros sobre o ensino de exercícios ginásticos e militares, bem como jogos escolares, na formação de professores, ações pedagógicas representativas tanto das dificuldades quanto dos princípios norteadores da escolarização da Educação Física.

Para o ensino complementar, o Regulamento Interno conformado no Decreto n. 400, de 6 de novembro de 1896, denominava a Ginástica como uma matéria que previa aulas específicas ministradas por um professor designado pelo diretor da escola, isso sem prejuízo aos exercícios físicos orientados em classe pelos professores de cada ano. O programa da matéria de Ginástica consistia em formaturas diversas, tomar distâncias, formar cadeias, posições fundamentais, exercícios dos membros superiores e inferiores, ginástica de aparelhos com halteres, bastões, elásticos de tração, salto com vara, maças, barras paralelas, cavalo, escada horizontal e barra fixa; já em Exercícios Militares, ensinava-se a condição de recruta, compreendendo desde a posição do soldado a pé firme até marchas e alinhamentos, continências, ordem estendida, colunas, mudança de direção, formatura de costado, cerrar/ abrir distâncias, manejos de arma e exercícios simulados de fogo, e posições oficiais (SÃO PAULO, 1896).

Os exercícios ginásticos e militares representavam também a educação dos sentidos corporais que agrupava duas esferas de intervenção: a primeira compreendendo o ensino de certos movimentos úteis, como as evoluções militares, e a segunda, o ensino dos movimentos físicos para fortalecimento dos músculos, para os cuidados do corpo e para as diferentes sensibilidades.

No ano letivo de 1901, conforme os horários de aula apresentados por Antônio Alves Aranha, diretor da Escola Complementar de Piracicaba, os exercícios militares destinavamse à seção masculina dos quatro anos de curso e eram realizados aos sábados entre 13h45 e 15h00, enquanto a seção feminina desenvolvia conteúdos de Trabalhos Manuais e de 
Economia Doméstica. Já as aulas de Ginástica, para ambos os sexos e em separado, eram ofertadas apenas para as turmas de $1^{\circ}$ e $2^{\circ}$ ano, respectivamente, às segundas e quintasfeiras, e às quartas-feiras e aos sábados, entre $12 \mathrm{~h} 10$ e $12 \mathrm{~h} 25$.

Embora fossem previstos somente 15 minutos para cada uma das quatro sessões semanais de Ginástica, o horário previsto indica uma significativa regulamentação da Ginástica na organização e distribuição do tempo escolar da formação de professores. A sua posição no quadro de horário revela uma representação do que dela se esperava como recurso recreativo, higiênico e como relaxamento da fadiga intelectual ${ }^{6}$.

Para Moreno et al. (2012), o tempo escolar destinado à Ginástica e à dimensão educação do corpo deve ser também considerado na complexidade do conjunto de disciplinas, pois diferentes práticas educativas acabaram incidindo no corpo e nas sensibilidades que tomam forma em diversificados tempos e espaços na formação de professores.

Por um lado, a introdução dos exercícios físicos no tempo escolar prescrito representava uma inovação voltada à educação integral - intelectual, moral e física - inspirada nos pressupostos de Herbert Spencer, autor de Educação intelectual, moral e física, obra propagada nos centros de ensino europeus e norte-americanos. Por outro lado, deve-se verificar as condições de concretização da Ginástica no tempo escolar.

Sobre o desenvolvimento da Ginástica e dos Exercícios Militares, o diretor da Escola Complementar de Piracicaba, Antônio Alves Aranha, relatou:

Este programa, que se executou nos quatro anos de existência desta Escola, com algum prejuízo para Ginástica e Exercícios Militares, que constaram apenas de movimentos em salas de aula por falta de uma casa apropriada a essas disciplinas, elas foram desenvolvidas por oito professores que constituídos em enciclopédias vivas, tiveram de lutar ensinando grande número de matérias não correlatas, em obediência às disposições regulamentares. ${ }^{7}$

Nos primeiros anos de funcionamento da Escola, a prática de Ginástica se resumia ao tempo destinado para tal atividade em sala de aula. Destaca-se ainda a inexistência de um mestre específico para ministrar a aula de Ginástica e quem a ministrava eram os professores "enciclopédias vivas", obrigados a cumprir as atividades dentro da precariedade de espaço.

Desde 1900 reivindicava-se um lugar adequado para o complementarista desenvolver exercícios ginásticos. Nas palavras de Antonio Alves Aranha:

Uma outra necessidade que listei por diversas vezes, ao conhecimento do Governo, é a de construir uma casa para Ginástica, e meus pedidos neste sentido não foram satisfeitos, continuando a Escola desprovida desse melhoramento, sem o qual o ensino de Ginástica sempre será gravemente prejudicado. No ano próximo passado fui encarregado de levantar a planta para essa construção e não sendo ela aceita veio aqui um engenheiro das obras públicas que tirou os dados para base do orçamento; mas até hoje não voltou aqui esse engenheiro e a verba destinada ao ginásio caiu em exercícios findos. ${ }^{8}$

6 Conforme Vago (2002, p. 237), "a preocupação com a fadiga escolar afetou a concepção e a distribuição do tempo e do trabalho escolar nas três primeiras décadas do século XX".

7 ARANHA, Antonio Alves. Relatório da Diretoria da Escola Complementar de Piracicaba, 1900. p. 4. Acervo do Arquivo Permanente da Escola Estadual "Sud Mennucci de Piracicaba".

8 ARANHA, Antonio Alves. Relatório da Diretoria da Escola Complementar de Piracicaba, 1900. p. 16. Acervo do Arquivo Permanente da Escola Estadual "Sud Mennucci de Piracicaba". 
Havia, pois sim, uma preocupação com a distribuição e acomodação arquitetônica das aulas de Ginástica, bem como uma diferenciação entre a representação sobre o espaço sala de aula e o espaço ginásio.

Na sala de aula, o aluno seria conformado ao terreno da escrita, leitura, concentração, ou seja, do pensar, aprender a ensinar, do mobiliário escolar, como as carteiras Chandler, do tempo administrativamente construído e socialmente incorporado; enfim, conformado a um ambiente geométrico e culturalmente limitador de sua mobilidade corporal, porém produtivo em termos intelectuais.

O ginásio representaria a casa moderna geometricamente apropriada para o aluno se movimentar, desenvolver forças físicas, compensar cansaços intelectuais, divertir-se, sentir prazer, aprender hábitos higiênicos, desenvolver marchas militares e formar habilidades para orientar pela Educação Física os comportamentos de seus futuros alunos.

A relação entre a sala de aula e o ginásio representa uma distinção do que foi valorizado como eminentemente teórico e prático na cultura escolar da época. Representa a distribuição e os usos dos espaços como lugares de aprendizagem, de socialização e de específicas funções na escola.

Em 1901 a existência de um ginásio foi cobrada novamente pela direção escolar, a saber,

Referente aos trabalhos manuais da secção masculina e à ginástica, em ambas as secções, foram prejudicados por não se ter ainda boa instalações nas oficinas e por faltar uma casa apropriada aos exercícios de ginástica: só fizeram exercícios em sala de aula, o que é insuficiente em uma Escola Complementar [...] a escola sente-se prejudicada por falta desse ginásio, sem o qual não se compreende o que seja um estabelecimento de ensino. ${ }^{9}$

Ter um ginásio para a figuração complementarista representava certo distanciamento da estrutura educacional do Império, atestando a existência da moderna educação republicana e a possibilidade de oferecer sólida formação aos alunos-mestres. Nesse sentido, o ginásio poderia ser utilizado como um terreno de aprendizagem pedagógica voltada à cultura do físico, visando completar a educação integral.

A questão do ginásio foi solucionada provisoriamente, quando a instituição piracicabana foi transformada em Normal Primária.

Atendendo a uma solicitação desta diretoria, foi construído um galpão de abrigo, apropriado ao mesmo tempo para os exercícios de ginástica. Graças a isso as aulas dessa disciplina funcionaram mais regularmente, não se temos verificado durante $o$ ano inconvenientes que haviam quando os exercícios tinham lugar ao relento ou nas próprias classes. ${ }^{10}$ (Grifo nosso).

Do excerto, duas observações. A primeira diz respeito à noção de disciplina impressa no relatório de 1914. Na Reforma de Ensino de 1911, sob o decreto n. 2.025, que alterou a estrutura curricular das escolas normais paulistas, as matérias foram distribuídas em dois grupos, 0 de cadeiras de ciências e línguas e o de disciplinas que se organizavam como aulas específicas; no segundo grupo foram alocadas a Ginástica, Música, Trabalhos Manuais,

9 ARANHA, Antonio Alves. Relatório da Diretoria da Escola Complementar de Piracicaba, 1901. p. 5, 10. Acervo do Arquivo Permanente da Escola Estadual "Sud Mennucci de Piracicaba".

10 FAUSTINO, Honorato. Relatório da Diretoria da Escola Normal Primária de Piracicaba, 1914. p. 21. Acervo do: Arquivo Permanente da Escola Estadual "Sud Mennucci de Piracicaba". 
Desenho e Caligrafia. Já na Reforma de 1920, sob o decreto n. 1.750, as matérias do programa do curso normal foram distribuídas em cadeiras e em aulas; a Ginástica foi considerada como aula. Então, do ponto de vista da legislação, no período estudado, não foi possível identificar a consolidação da Ginástica, no caso, como disciplina com status escolar equiparado às demais cátedras.

A segunda observação é que foi provisório o galpão de abrigo das aulas de Ginástica citado em 1914, isso porque estava em construção um novo prédio para a Normal de Piracicaba, inaugurado em 1917 em estilo neoclássico, e que constava um espaço para o ginásio (HONORATO, 2011).

A dificuldade do desenvolvimento da aula de Ginástica, no período da Escola Complementar à Normal Primária, não se resumia ao status diferenciado de disciplina e à falta de espaço apropriado, havia também a insuficiência de equipamentos para exercícios ginásticos.

Ao se analisar o livro de inventário geral da Escola Complementar de Piracicaba ${ }^{11}$, identificam-se, na lista de materiais permanentes, apenas dois quadros de ginástica de J. P. Müller $^{12}$. Já na pesquisa realizada no Arquivo Público do Estado de São Paulo encontrou-se um Ofício de 1915, emitido por Honorato Faustino, diretor da Escola Normal Primária de Piracicaba, ao Dr. Altino Arantes, Secretário de Estado dos Negócios do Interior, solicitando a quantia de $150 \$ 000$ para aquisição de uma "barra fixa transferível" para execução de exercícios físicos por parte dos alunos.

Figura 1 - Barra fixa transferível

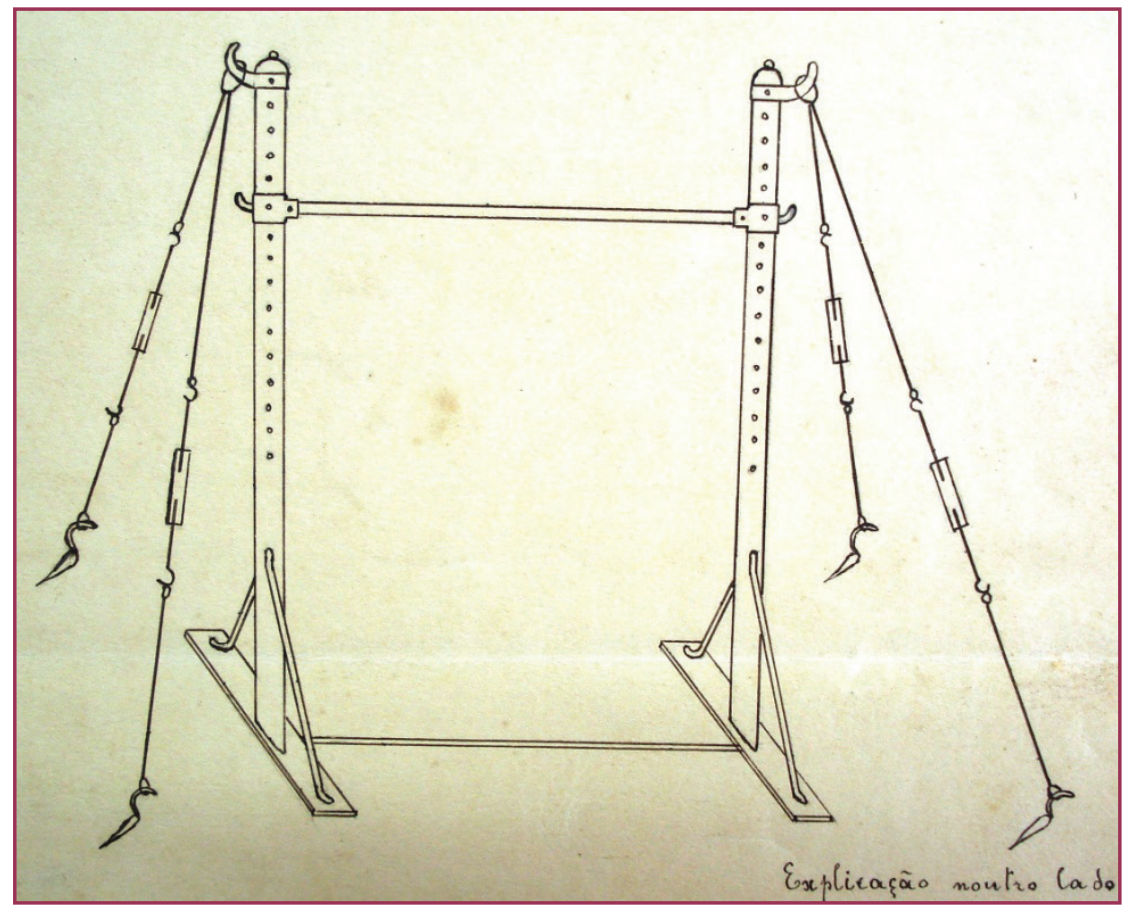

Fonte: FAUSTINO, Honorato. Ofício n. 253 de 2 de agosto de 1915. Arquivo Público do Estado de São Paulo. Lata: 336. Ordem 6941.

11 FAUSTINO, Honorato. Livro inventário de materiais. 1920. Localizado: Arquivo Permanente da Escola Estadual "Sud Mennucci de Piracicaba".

12 A obra O meu sistema, de J. P. Müller, foi criticada pelo inspetor escolar F. N. Camargo Couto por valorizar a aplicação da ginástica racional na "parte fraca do organismo" de um indivíduo, para assim restabelecer a sua harmonia com os demais órgãos, isto é, a ginástica médica. Para Camargo, o desenvolvimento, por meio da ginástica científica e artística, deveria ser harmônico por completo e sem fins terapêuticos (SÃO PAULO, 1913). 
Figura 2 - Galpão de ginástica da Escola Normal de Piracicaba

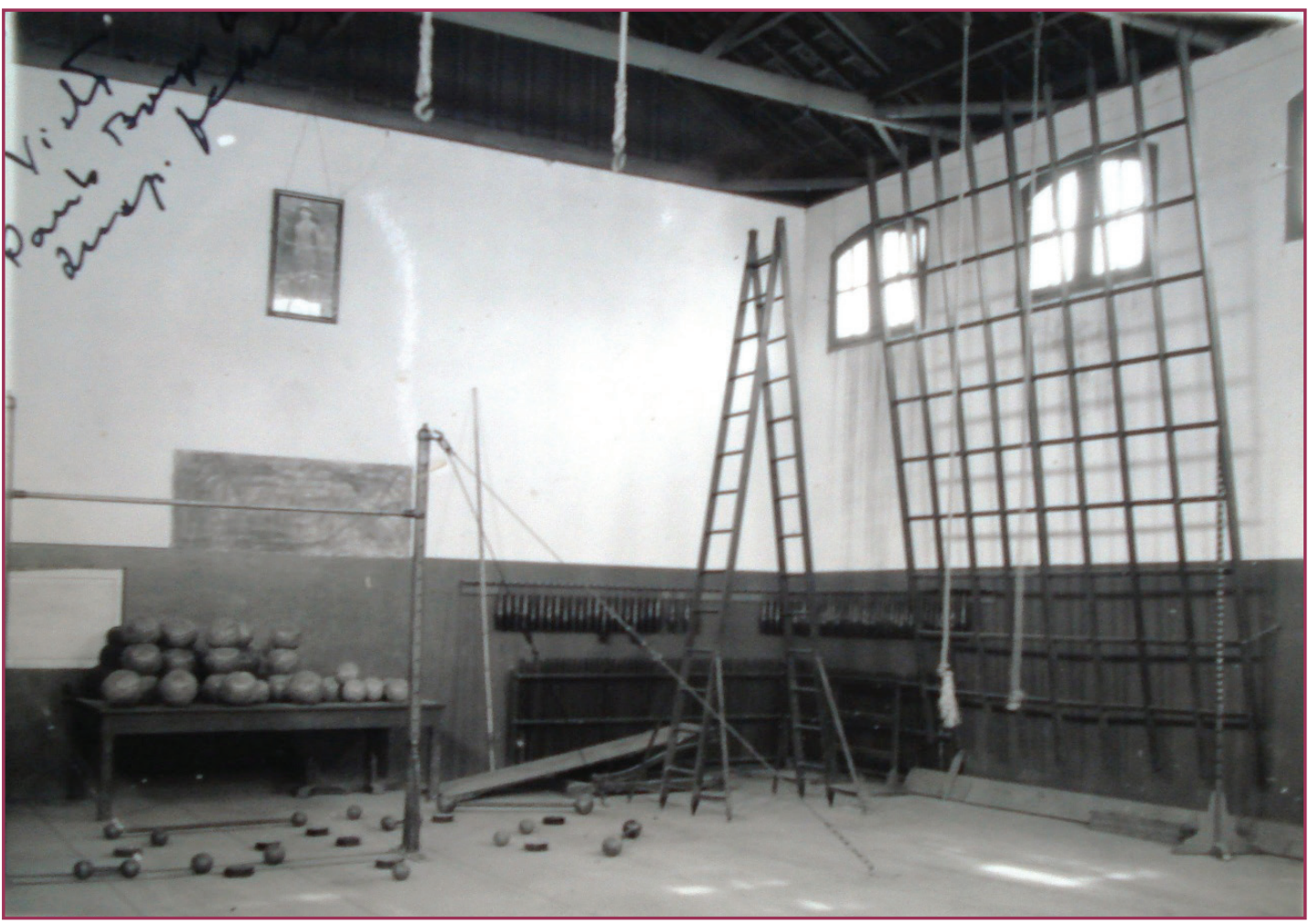

Fonte: Arquivo Permanente da Escola Estadual "Sud Mennucci"

$\mathrm{Na}$ imagem do galpão de ginástica visualizam-se cobertura de telhas e sem forro de taboas, piso sem asperezas, janelas arejando o ambiente, um quadro representando um ginasta e equipamentos como barra fixa, halteres espalhados pelo piso, maças, bastões gímnicos enfileirados, escada, cordas suspensas, entre outros. Tratava-se de um espaço para receber pequenas turmas do ponto de vista higiênico, a Escola também dispunha de área aberta de recreio e de pátio para exercícios físicos, evoluções militares e jogos escolares (ver: figuras 3 e 4). 0 galpão representava a reserva de um espaço mais adequado na arquitetura e na organização da Escola Normal de Piracicaba.

Observou-se, a partir do inventário de materiais para o ano de $1920^{13}$, uma quantidade mais significativa de equipamentos no ginásio da Escola Normal Primária de Piracicaba, instalada no novo prédio desde 1917. Sendo que a aquisição de equipamentos e a atenção redobrada às aulas de Ginástica deram-se apenas com a transformação da Escola Complementar em Normal Primária.

Em termos legais, o diretor deveria organizar o curso de formação de professores disponibilizando para as seções masculina e feminina atividades de ginástica pelo menos duas vezes por semana. A partir da Reforma de Ensino de 1911, a escola normalista deveria contratar professores específicos para o ensino de Ginástica, Trabalhos Manuais, Desenho e Música.

Em 1912, com a contratação de David Müller, e em 1917, com a contratação da complementarista Olívia Bianco e da normalista Maria Ferraz de Toledo ${ }^{14}$, os ensinamentos

13 FAUSTINO, Honorato. Livro inventário de materiais. 1920. Localizado: Arquivo Permanente da Escola Estadual "Sud Mennucci de Piracicaba".

14 Olivia Bianco diplomou-se professora, em 1900, junto com a primeira turma de formandos da Escola Complementar de Piracicaba. Foi professora adjunta do Grupo Escolar "Barão do Rio Branco", do Grupo Escolar "Moraes Barros", do Grupo Escolar-Modelo Anexo e do Curso Complementar. (FAUSTINO, Honorato. Livro de apontamento sobre o pessoal da Escola Normal de Piracicaba. 1921. p. 7. Localizado: Arquivo Permanente da Escola Estadual "Sud Mennucci de Piracicaba") 
de exercícios físicos foram potencializados na Escola de Piracicaba. Até então, as aulas eram irregulares nas duas seções e ocorriam apenas no caso de professoras adidas assumirem 0 cargo, como foi a situação de Luintina Soares, Laura Martins de Mello e Aurora Camargo da Silva Rodrigues. ${ }^{15}$

Os professores estimulavam os comportamentos dos alunos rumo ao cultivo do corpo saudável, harmônico e disciplinado, condizentes com o modo social de vida.

\section{Ginástica e jogos escolares}

A par do desenvolvimento intelectual, moral e cívico dos alunos, não nos temos descuidado da sua Educação Física. É assim que temos procurado desenvolver aqui uma ginástica racional e apropriada ao desenvolvimento harmônico das diversas partes do corpo ao mesmo tempo dando largo incremento aos diversos jogos escolares, cuidadosamente escolhidos, a fim de que possam não só despertar interesse como atingir o objetivo visado. ${ }^{16}$ (Grifo nosso)

Na virada da década de 1910 para a de 1920 registra-se que a representação da Educação Física enquanto uma dimensão da formação de professores passa ser cada vez mais presente. A professora Olívia Bianco, no artigo intitulado "Educação Physica", publicado na Revista de Educação, em 1921, também compreendia que a finalidade da Educação Física era promover o desenvolvimento harmônico e proporcional das capacidades humanas de maneira proveitosa, utilitária e eficiente para vida.

Para Bianco, a "Educação Física, no seu sentido absoluto, é o processo que tem por objetivo formar o homem típico". Por isso, a professora fazia uma analogia entre o cultivo do corpo e o crescimento evolutivo:

No homem observam-se também as mesmas gradações de perfeição física. Em um dos extremos - deformidades horripilantes, em outro - beleza divina; entre os dois - escala de infinitas gradações. É da esfera da Educação Física, hoje arte de objetivos conscientes e já muito distanciada do empirismo, encaminhar o ser humano para a sua perfeita organização somática, como a intelectual e moral preparam as qualidades de espírito e de caráter. (BIANCO, 1921, p. 110)

As gradações físico-corpóreas deveriam ser atingidas por aqueles considerados fisicamente inferiores, por isso, aquele em condição de inferioridade deveria se sujeitar mais ainda aos exercícios racional e cientificamente sistematizados, e tornar-se um tipo ideal.

Ao futuro professor recomendava-se que fosse sempre o primeiro a dar exemplo de inteireza física e de caráter em todos os atos de sua vida profissional. As questões de higiene e controle de saúde não deveriam ser descuidadas, como bem lembrava o diretor Honorato Faustino, em relatório:

Quanto à Educação Física:

Por outro lado não temos descuidado tudo quanto se refere à educação dos sentidos e a correção não só de seus erros fisicamente fisiológicos, como de seus desvios patológicos, na medida dos elementos de que podemos dispor.

Completando essa parte, temos procurado generalizar certas noções de higiene, pondo-as ao alcance da inteligência de crianças, de modo a habituá-las a saberem evitar alteração da saúde. ${ }^{17}$

15 FAUSTINO, Honorato. Relatório da Diretoria da Escola Normal Primária de Piracicaba. 1912. Localizado: Arquivo Permanente da Escola Estadual "Sud Mennucci de Piracicaba".

16 FAUSTINO, Honorato. Relatório da Diretoria da Escola Normal Primária de Piracicaba. 1919, p. 21. Localizado: Arquivo Permanente da Escola Estadual "Sud Mennucci de Piracicaba".

17 FAUSTINO, Honorato. Relatório da Diretoria da Escola Normal de Piracicaba. 1921, p. 9. Localizado: Arquivo Permanente da Escola 
A saúde era a condição do bom funcionamento fisiológico e da necessidade física do corpo, caso contrário, o corpo doentio atrapalharia o desenvolvimento intelectual, psíquico e da alma, exigindo do educador nunca perder de vista "a inteireza da verdade contida no luminoso aforismo pedagógico - mens sana in corpore sano". ${ }^{18}$

$\mathrm{Na}$ escola, a racionalidade física e higiênica proporcionada pelos exercícios regulados objetivava prevenir e/ou eliminar, junto aos alunos, vícios possivelmente contraídos nas ruas e intervir na correção ortopédica. Portanto, tinha-se a expectativa de que a Educação Física também transformaria os comportamentos e costumes do futuro professor, o encarregado de colocar em circulação um modelo de cultura física saudável respaldado em conhecimentos escolarizados.

A Educação Física, disseminada aos normalistas em Piracicaba no início dos anos 1920, procurava substituir a clássica coleção de exercícios musculares fastidiosos que não despertavam interesse e até eram prejudiciais aos alunos (BIANCO, 1921). O esforço físico desagradável, considerado um fardo, não poderia ter mais lugar proeminente, desprezando 0 prazer e as tensões emocionais, pois pouco colaboraria para a formação integral.

No ensino normalista inseriam-se cada vez mais os princípios da Educação Física moderna com base na ginástica sueca, calistênica e nos jogos escolares, para desenvolver harmonicamente os músculos, órgãos e energias vitais, e fortalecer as forças internas para se relacionarem com o mundo exterior ${ }^{19}$.

Figura 3 - Normalistas de Piracicaba em formação gímnica

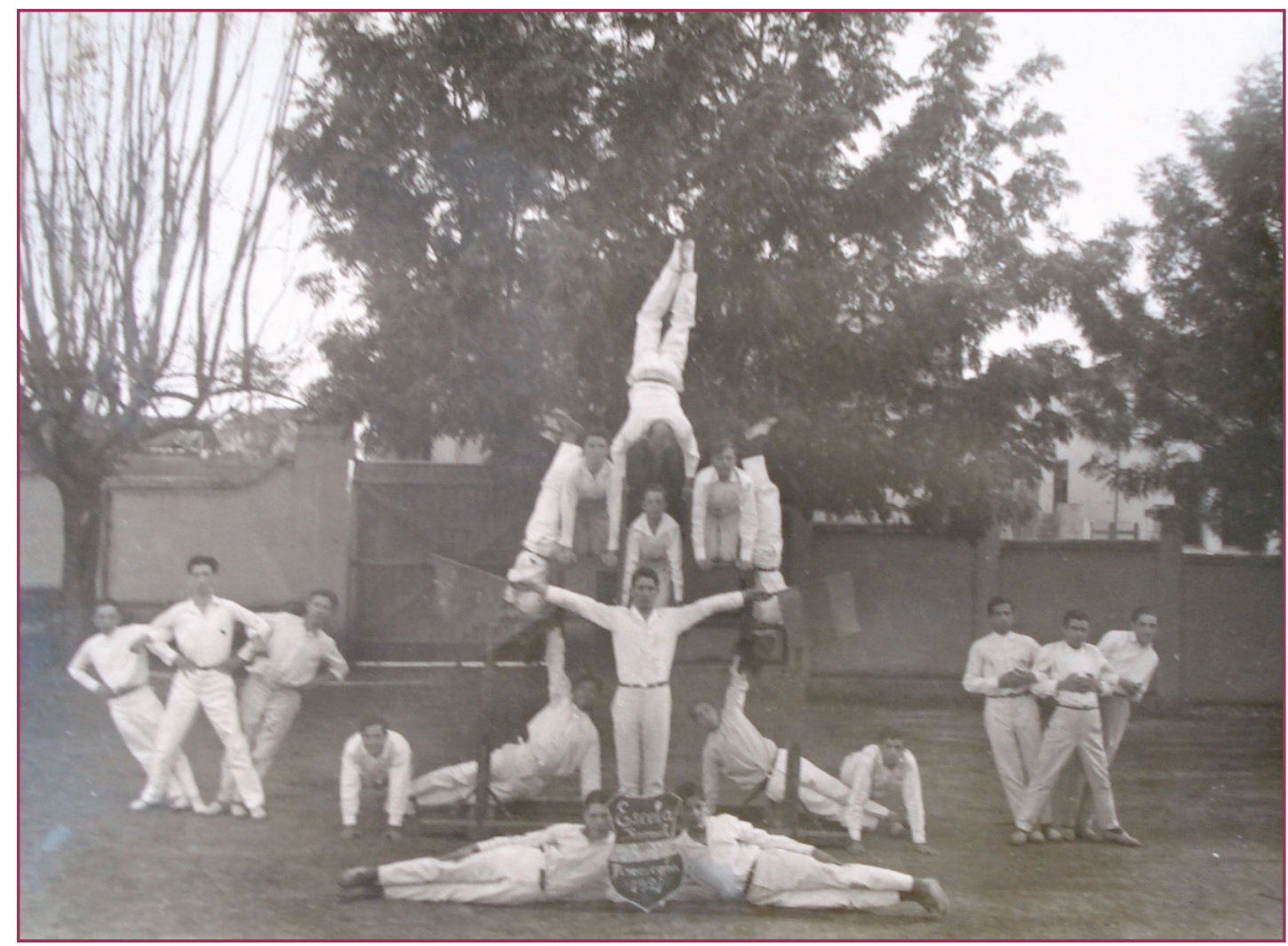

Fonte: Arquivo Permanente da Escola Estadual "Sud Mennucci".

Estadual "Sud Mennucci de Piracicaba".

18 FAUSTINO, Honorato. Relatório da Diretoria da Escola Normal de Piracicaba. 1921, p. 9. Localizado: Arquivo Permanente da Escola Estadual "Sud Mennucci de Piracicaba".

19 Na Revista de Ensino, órgão da Associação Beneficente do Professorado Público de São Paulo, publicada entre 1902-1918, foram publicadas séries de artigos sobre ginástica racional, Educação Física e jogos escolares. Sobre Educação Física, ver também os estudos de Vago (2002); Soares (2004). 
Figura 4 - Jogo de "bola ao cesto" por ocasião da festa esportiva de 21 de abril, na Escola Normal de Piracicaba

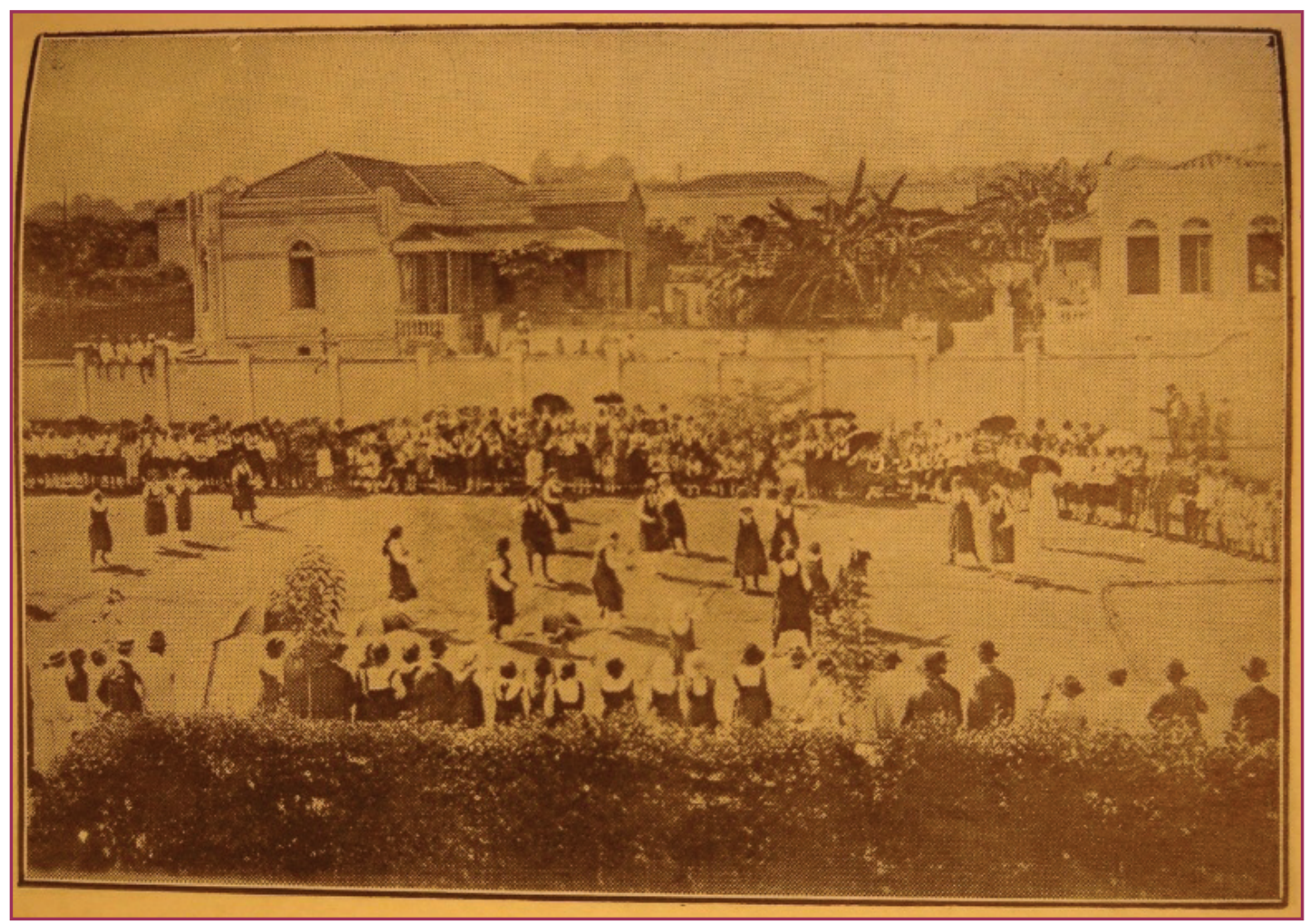

Fonte: Revista de Educação, 1921, p. 144.

Os jogos ao ar livre, a ginástica moderna e outras práticas adquiriram na figuração escolar um caráter menos muscular. A Educação Física deveria ser uma dimensão do ensino que oportunizasse exercícios moderados ao organismo, intelecto, emoções e músculos. Os exercícios de velocidade, força, agilidade, equilíbrio, ritmo, corridas e saltos resultariam em elegância do movimento, muito mais ligado à boa saúde do que à fadiga dos músculos poderosos, como apontara a professora Bianco:

Os jogos escolares, assim considerados, promovem em todos uma intensa alegria e vivacidade, sendo férteis em benefícios, tanto físicos, como mentais e morais. Deles decorrem também consequências de sociabilidade e de camaradagem, iniciando-se as crianças em hábitos de amabilidade para com os competidores. (BIANCO, 1921, p. 111)

Encontrou-se nos jogos e exercícios gímnicos - alegres e belos - um modo de cultivar civilidade, polidez e sentimentos estéticos. A Educação Física potencializaria a formação do professor para a vida civil pública, que exigia utilidade, civilidade e urbanidade.

A Educação Física fomentada na Normal de Piracicaba era também símbolo de nacionalismo ao preparar uma geração de juventude forte e sadia. Como atividade de preparação para os sérios misteres da vida humana, segundo Olívia Bianco (1921, p. 112), era reconhecida pelos benefícios "quer puramente individuais, quer sob o ponto de vista da coletividade, visando à melhoria da raça que traria como importantíssimo corolário o engrandecimento da nação".

Destinada ao civismo, moralidade e patriotismo, a Educação Física promoveria bons valores colimando comportamentos de coragem, respeito e cordialidade na esfera pública. Cada aluno teria o dever de se esforçar num trabalho constante de aperfeiçoamento harmônico do corpo, para cumprir seu destino individual e social. 


\section{CONSIDERAÇÕES FINAIS}

A Escola Complementar e Normal de Piracicaba indica que a introdução da Ginástica, uma proto-disciplina ${ }^{20}$, na formação de professores foi processual e estruturalmente morosa. Isto porque os republicanos paulistas idealizaram em dispositivos legais os tipos de escolas seriadas, os programas de ensino e um modelo de cultura escolarizada que o aparelho escolar daquele momento histórico dificilmente corresponderia em termos de organização, funcionamento, financiamento, estruturação física e corpo de especialistas para lecionar as matérias previstas.

Por fim, o estudo da Educação Física na história das escolas de formação de professores possibilita significativas reflexões sobre o campo educacional no sentido de compreender qual homem integral deveria ser e estava sendo formado para a vida em sociedade, quais concepções de ciência e de saúde do corpo regeriam o ensino dos professorandos, quais foram os espaços e tempos escolares vividos e/ou prescritos em regulamentações estatais, como foram estruturadas e equipadas as modelares escolas responsáveis pela inovação educativa, entre outros. Refletir sobre o campo educacional, como tem sido apontado até aqui, é pensar também a Educação Física como uma regulação muito específica sobre o aluno, que não se restringia a mecanismos automáticos naturais, pois havia uma gama de regulações biológicas e fisiológicas, bem como regulações sociais, políticas e psíquicas exigidas. A formação integral do professorando também dependia da ordem física e estética para vida privada e pública em sociedade.

\section{REFERÊNCIAS}

AZEVEDO, Leny Cristina Soares Souza. Escola Normal "Carlos Gomes": memória e formação de professores (1903-1936). 2005. 138 f. Tese (Doutorado) - Faculdade de Educação, Universidade Estadual de Campinas, Campinas, 2005.

BIANCO, Olívia. Educação Physica. Revista de Educação, Piracicaba, v. 1, n.1, p. 110-112, maio 1921.

CHARTIER, Roger. A história cultural: entre práticas e representações. Lisboa: Difel; Rio de Janeiro: Bertrand do Brasil, 1990.

CHIARELI, Clarice Pavan. Escola Complementar de Piracicaba segundo Jornal Gazeta (1897-1911). 2007. 105 f. Dissertação (Mestrado) - Faculdade de Educação, Universidade Metodista de Piracicaba, Piracicaba, 2007.

CORBAGE, Debora Maria Nogueira. História e memória da Escola Complementar de Guaratinguetá (1906-1913). 2010. 117 f. Dissertação (Mestrado) - Curso de Educação, Pontifícia Universidade Católica de São Paulo, São Paulo, 2010.

DIAS, Enéias Borges. Revista da Escola Normal de São Carlos (1916-1923): um estudo sobre idéias e práticas educacionais. 2009. 156 f. Dissertação (Mestrado) - Curso em Educação Escolar, Faculdade de Ciências e Letras, Universidade Estadual Paulista, Araraquara, 2009. 
ELIAS, Norbert. A sociedade dos indivíduos. Rio de Janeiro: Jorge Zahar, 1994.

FRANKFURT, Sandra Herszkowi. As práticas das festas escolares na Escola Normal de Pirassununga (1930-1950). 2006. 193 f. Dissertação (Mestrado) - Curso de Educação, Pontifícia Universidade Católica de São Paulo, São Paulo, 2006.

GÓIS JÚNIOR, Edivaldo; BATISTA, José Carlos Freitas. A introdução da gymnastica na Escola Normal de São Paulo (1890-1908). Movimento, Porto Alegre, v. 16, n. 3, p. 71-87, jul./set. 2010.

HONORATO, Tony. Escola Complementar e Normal de Piracicaba: formação, poder e civilidade. 2011. 246 f. Tese (Doutorado) - Curso em Educação Escolar, Faculdade de Ciências e Letras, Universidade Estadual Paulista, Araraquara, 2011.

JOGO de "bola ao cesto" por ocasião da festa esportiva de 21 de abril, na Escola Normal de Piracicaba. Revista de Educação, Piracicaba, v. 1, n.1, p. 144, maio 1921.

MONARCHA, Carlos. Escola normal da praça: o lado noturno das luzes. Campinas: Editora da Unicamp, 1999.

MORENO, Andrea et al. "Gesticulação nobre, sympathica e attitude digna": educação do corpo na formação de professoras (Escola Normal Modelo da Capital, Belo Horizonte, 1906-1930). Revista Brasileira de História da Educação, Campinas, v. 12, n. 1, p. 221-242, jan./abr. 2012.

NERY, Ana Clara Bortoleto. Oscar Thompson e a Escola Normal de São Paulo: práticas e reformas. In: CONGRESSO LUSO BRASILEIRO DE HISTÓRIA DA EDUCAÇÃO, 8., 2010, São Luís. Anais... São Luís: SBHE, 2010. v. 1, p. 1-15.

NOSELLA, Paolo; BUFFA, Ester. Schola Mater: a antiga escola Normal de São Carlos. São Carlos: EDUFSCAR; FAPESP, 2002.

PINHEIRO, Maria de Lourdes. A Escola Normal de Campinas no período 1920-1936: práticas e representações. 2003. 158 f. Dissertação (Mestrado) - Faculdade de Educação, Universidade Estadual de Campinas, Campinas, 2003.

ROCCO, Salvador et al. Poliantéia comemorativa do centenário do ensino normal de São Paulo (1846-1946). São Paulo: [s.n.], 1946.

RODRIGUES, João Lourenço. Livro jubilar da Escola Normal da Capital. São Paulo: Instituto d. Anna Rosa, 1930.

SÃO PAULO. Annuário do ensino do Estado de São Paulo. Publicação organizada pela Directoria Geral da Instrucção Pública com autorização do Governo de Estado. São Paulo: Tipografia Siqueira, 1913.

SÃO PAULO. Decreto n.․ 2025, de 29 de março de 1911. Converte as Escolas Complementares em Escolas Normais Primárias e Ihes dá regulamento. Assembléia Legislativa do Estado de São Paulo, São Paulo, SP. Disponível em: <http://al.sp.gov.br/norma/?id=135390>. Acesso em: 5 jul. 2014.

SÃO PAULO. Decreto n.ำ 218, de 27 de novembro de 1893. Regulamento da Instrução Pública do Estado de São Paulo. Assembléia Legislativa do Estado de São Paulo, São Paulo, SP. Disponível em: <http://al.sp.gov.br/norma/?id=137485>. Acesso em: 5 jul. 2014.

SÃO PAULO. Decreto n. -400 , de 6 de novembro de 1896. Regimento Interno das Escolas Complementares do Estado. Assembléia Legislativa do Estado de São Paulo, São Paulo, SP. 
Disponível em: <http://al.sp.gov.br/norma/?id=137273>. Acesso em: 5 jul. 2014.

SÃO PAULO. Decreto Lei n. 861 , de 12 de dezembro de 1902. Transfere a Escola Complementar "Prudente de Moraes" para a cidade de Guaratinguetá. Assembléia Legislativa do Estado de São Paulo, São Paulo, SP. Disponível em: <http://al.sp.gov.br/norma/?id=64952>. Acesso em: 5 jul. 2014.

SÃO PAULO. Lei n.. 1750 , de 8 de dezembro de 1920. Reforma a instrução pública do Estado de São Paulo. Assembléia Legislativa do Estado de São Paulo, São Paulo, SP. Disponível em: <http://al.sp.gov.br/norma/?id=65983>. Acesso em: 21 mar. 2015.

SÃO PAULO. Lei n. 374 , de 3 de setembro de 1895. Providência sobre o ensino das matérias do Curso das Escolas Complementares, dos Ginásios, das Escolas Normais, sobre outros assumptos relativos. Assembléia Legislativa do Estado de São Paulo, São Paulo, SP. Disponível em: <http://al.sp.gov.br/norma/?id=64465>. Acesso em: 5 jul. 2014.

SÃO PAULO. Lei n.․ 88, de setembro de 1892. Reforma a Instrução Pública do Estado de São Paulo. Assembléia Legislativa do Estado de São Paulo, São Paulo, SP. Disponível em: <http://al.sp.gov.br/norma/impressao/?id=64173\&ver imp=true>. Acesso em: 5 jul. 2014.

SIMÕES, José Luis. Escolas para as elites, cadeias para os vadios: relatos da imprensa piracicabana (1889-1930). 2005. 264 f. Tese (Doutorado) - Faculdade de Educação, Universidade Metodista de Piracicaba, Piracicaba, 2005.

SILVA, Emerson Correia. A configuração do habitus professoral para o aluno-mestre: a Escola Normal Secundária de São Carlos (1911-1923). 2009. 124 f. Dissertação (Mestrado) Curso de Educação, Faculdade de Filosofia e Ciências, Universidade Estadual Paulista, Marília, 2009.

SOARES, Carmem Lucia. Educação Física: raízes européias e Brasil. 3. ed. Campinas: Autores Associados, 2004.

TANURI, Leonor Maria. O Ensino normal no Estado de São Paulo (1890-1930). São Paulo: Publicações da Faculdade de Educação da Universidade de São Paulo; Estudos e Documentos, 1979.

TEIXEIRA JÚNIOR, Oscar. Escola Complementar de Campinas (1903-1911): espaço, culturas e saberes escolares. 2002. 259 f. Dissertação (Mestrado) - Faculdade de Educação, Universidade Estadual de Campinas, Campinas, 2002.

VAGO, Tarcisio Mauro. Cultura escolar, cultivo de corpos: educação physica e gymnastica como práticas constitutivas dos corpos de crianças no ensino público primário de Belo Horizonte (1906-1920). Bragança Paulista: UDUSF, 2002.

VIÑAO FRAGO, Antônio. A história das disciplinas escolares. Revista Brasileira de História da Educação, Campinas, v. 8 n. 3, p. 173-205, set./dez. 2008.

WEBER, Eva Fagundes. Descrição do livro registro de imposições de penas da Escola Normal Peixoto Gomide. 2003. 91 f. Dissertação (Mestrado) - Curso de Linguística, Pontifícia Universidade Católica de São Paulo, São Paulo. 2003. 